\title{
An Inflation Rate Prediction Based on Backpropagation Neural Network Algorithm
}

\author{
Purnawansyah $^{\mathrm{a}, 1,{ }^{*}}$, Haviluddin ${ }^{\mathrm{b}, 2}$, Hario Jati Setyadi ${ }^{\mathrm{b}, 3}$, Kelvin Wong $^{\mathrm{b}, 4}$, Rayner Alfred $^{\mathrm{c}, 5}$ \\ ${ }^{a}$ Universitas Muslim Indonesia, Makassar, Indonesia \\ ${ }^{b}$ Universitas Mulawarman, East Kalimantan, Indonesia \\ ${ }^{c}$ Universiti Malaysia Sabah, Malaysia \\ ${ }^{1}$ purnawansyah@umi.ac.id; ${ }^{2}$ haviluddin@unmul.ac.id*; ${ }^{3}$ hario.setyadi@gmail.com; ${ }^{4}$ lucky7kelvin@yahoo.com; ${ }^{5}$ \\ ralfred121@gmail.com; \\ * corresponding author
}

ARTICLE INFO

Received 01 May 2019

Revised 06 June 2019

Accepted 30 July 2019

Keywords:

BPNN

MSE

Prediction

Inflation Rates

Economic

\section{ABSTRACT}

This article aims to predict the inflation rate in Samarinda, East Kalimantan by implementing an intelligent algorithm, Backpropagation Neural Network (BPNN). The inflation rate data was obtained from the Provincial Statistics Bureau of Samarinda https://samarindakota.bps.go.id/ for the period January 2012 to January 2017. The method used to measure accuracy algorithm prediction was the mean square error (MSE). Based on the experiment results, the BPNN method with architectural parameters of 5-5-5-1; the learning function was trainlm; the activation functions were logsig and purelin; the learning rate was 0.1 and able to produce a good level of prediction error with an MSE value of 0.00000424 . The results showed that the BPNN algorithm can be used as an alternative method in predicting inflation rates in order to support sustainable economic growth, so that it can improve the welfare of the people in Samarinda, East Kalimantan.

Copyright (C) 2019 International Journal of Artificial Intelligence Research. All rights reserved.

\section{Introduction}

Inflation stability is a prerequisite for sustainable economic growth, so that it is expected to provide benefits to improve people's welfare. Therefore, inflation control is based on the consideration that high and unstable inflation has negative impacts on the socio-economic conditions of the community is essential [1]-[4]. For that reason, research on inflation prediction gets positive attention from macroeconomic researchers in a country including Indonesia.

Indonesia's average annual inflation rate for 10 years is $5.86 \%$ per year. Using the calculation of accumulated impairment after 10 years of inflation, the value of money accumulatively fell $-45.54 \%$ or $-5.90 \%$ YoY (year over year). In order to be easy to remember, in every article / discussion we set the approximate of the annual 10-year inflation rate of 6\% per year (https://www.bi.go.id). Meanwhile Samarinda's inflation condition in 2018, from July to November can be classified to be unexpected. In July and August, the inflations were $0.92 \%$ and $0.28 \%$. However, in September, October and November, they experienced deflation of $-0.01 \%,-0.16 \%$ and $-0.06 \%$ respectively. The rate of the inflation is due to the price of fundamental goods had decreased (https://samarindakota.bps.go.id/). Furthermore, the current inflation rate is the result of the previous inflation rate [5], [6].

For the Government, the inflation rate prediction is a bridge to determine the value of future inflation. Various kinds of predictions with artificial intelligence methods continue to be carried out and developed by researchers. [6] in his research that applied the Backpropagation Neural Network (BPNN) algorithm to predict monthly inflation rates in Indonesia. The results of the analysis showed that the performance of the BPNN algorithm with predictive accuracy is accurate based on the MSE value of 0.0171. Furthermore, [7] in their research applied statistical methods (ARIMA) and artificial intelligence (ANFIS) to predict general inflation data and inflation of seven expenditure 
groups for the period 2001-2014. The results showed that both methods can be used as alternative algorithms in making predictions. Furthermore, [8] have implemented the Backpropagation Neural Network (BPNN) algorithm to predict the opening of sharia trading positions. The data taken is the exchange rate between Euro (EUR) and USD as much as 720 datasets. The input parameters used for BPNN training consist of trending, momentum, moving average converge / diverge (MACD), and relative strength index (RSI). The results of the analysis showed that the method of BPNN with architecture; 4-8-1; learning function was Levenberg - Marquardt; Activation function was purelin, learning rate was 0.9 , epoch was 1000 . The architecture had been tested towards 50 new data, in which this model was able to produce good predicting accuracy with MSE value of 0.002748.

This paper aims to apply the Backpropagation Neural Network (BPNN) method to predict inflation rates in Samarinda, East Kalimantan. Furthermore, the results of this study were expected to help the consideration of a good monetary policy, to assist investors in making investments and related parties so that the economy in Samarinda would be better. This paper consists of four parts. The first part is the motivation of this study. The second part is the explanation of the methodology and techniques used. The third part is the explanation of the testing results by using the BPNN method and the data that were set. And, the last part is the conclusion and suggestions, which were obtained after testing, as well as plans for further research.

\section{Material and ethod}

In this section, the BPNN method, the sample data and the measurements of the prediction simulation results used in this study will be briefly explained.

\section{A. Backprogation Neural Network (BPNN) Technique}

The BPNN method was introduced by Paul Werbos in 1974, then, developed by David Parker in 1982. After that, in 1986, it was developed for the third time by Rumelhart and McCelland [9]-[11]. The BPNN method is widely used in solving various simulation problems including predictions. There are three stages in BPNN, namely; Feed forward, backward and weight update. Before entering the three stages, it is necessary to initialize the quality with random values with intervals of 0.1 to 1 . Then the data patterns will be normalized with the aim of obtaining the desired quality value. The quality value will continue to change each round until it reaches the training limit after going through Feed forward, backward and quality renewal. After the quality is obtained, it will enter the final stage, namely the testing stage. The test results obtained will then be compared with actual data [10], [12]-[14]. The BPNN flowchart can be seen in Figure 1.

\section{B. Data Sample}

In this study, the inflation rate data of Samarinda from 2012-2017 (72 months) were obtained from the Provincial Statistics Bureau of Samarinda https://samarindakota.bps.go.id/. Before the prediction process is carried out, the inflation rate data is normalized using equation 1 . The results of normalization can be seen in Table 1 and the graph of the inflation rate in Figure 2.

Table 1. Samarinda Inflation Rates Data 2012-2017

\begin{tabular}{lcccccc}
\hline Months & $\mathbf{2 0 1 2}$ & $\mathbf{2 0 1 3}$ & $\mathbf{2 0 1 4}$ & $\mathbf{2 0 1 5}$ & $\mathbf{2 0 1 6}$ & $\mathbf{2 0 1 7}$ \\
\hline January & 0.435430 & 0.562893 & 0.442138 & 0.311321 & 0.296226 & 0.383438 \\
February & 0.279455 & 0.326415 & 0.158700 & 0.183857 & 0.220755 & 0.234172 \\
March & 0.276101 & 0.232495 & 0.240881 & 0.172117 & 0.286164 & 0.259329 \\
April & 0.170440 & 0.247589 & 0.214046 & 0.252621 & 0.162055 & 0.261006 \\
May & 0.168763 & 0.138574 & 0.237526 & 0.234172 & 0.220755 & 0.276101 \\
June & 0.316352 & 0.432075 & 0.252621 & 0.346541 & 0.314675 & 0.326415 \\
July & 0.309644 & 0.900000 & 0.323061 & 0.385115 & 0.245912 & 0.312998 \\
August & 0.596436 & 0.584696 & 0.210692 & 0.230818 & 0.277778 & 0.207338 \\
September & 0.118449 & 0.100000 & 0.219078 & 0.202306 & 0.178826 & 0.183857 \\
October & 0.115094 & 0.219078 & 0.312998 & 0.242558 & 0.195597 & 0.183857 \\
November & 0.274423 & 0.230818 & 0.405241 & 0.255975 & 0.259329 & 0.192243 \\
December & 0.282809 & 0.252621 & 0.635010 & 0.430398 & 0.358281 & 0.334801 \\
\hline
\end{tabular}




$$
X^{\prime}=\frac{0.8(X-b)}{(a-b)}+0.1
$$

Where, $X^{\prime}$ is data normalization result; $X$ is actual data; $a$ is maximum score; $b$ is minimum score.

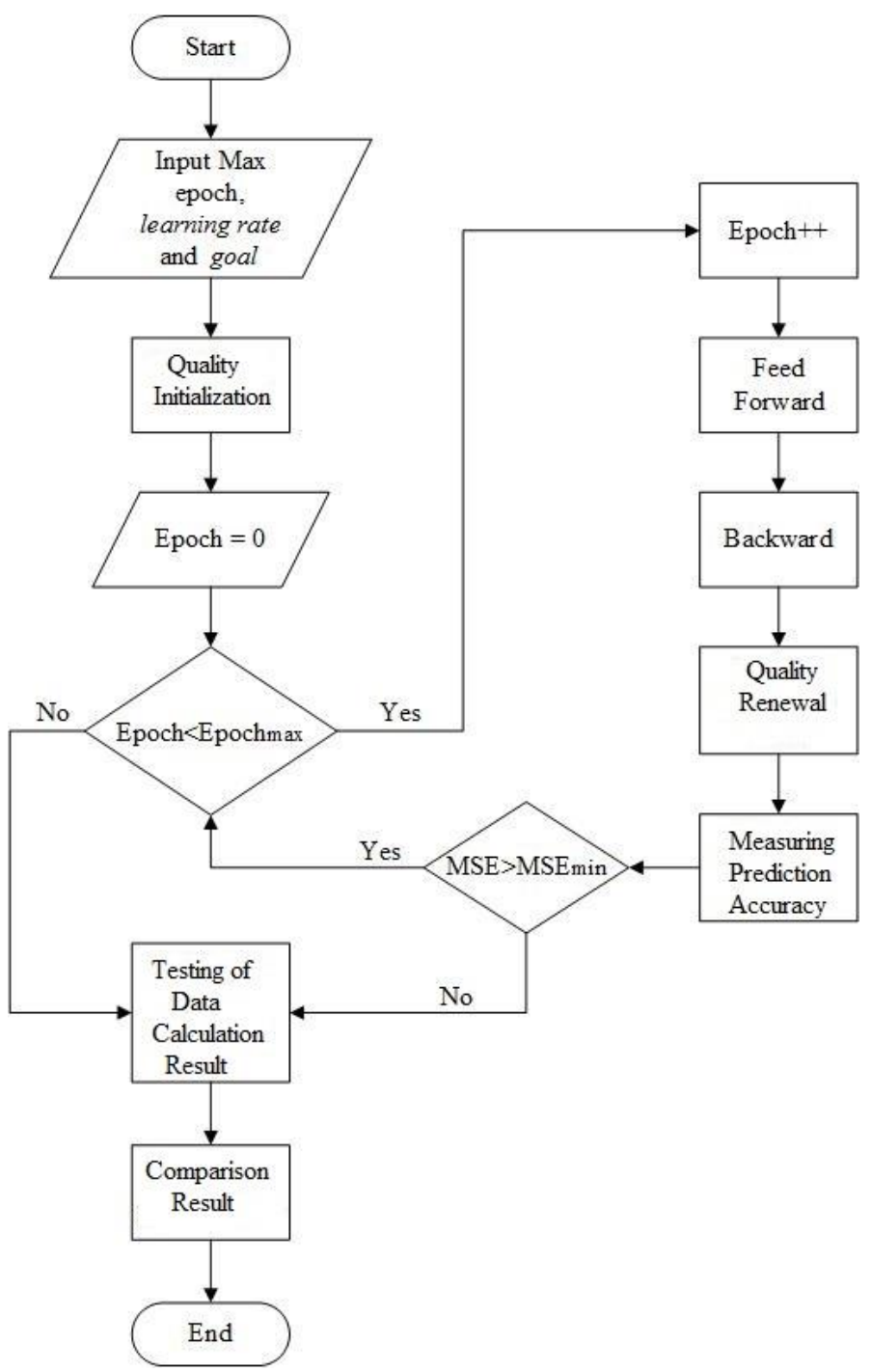

Fig. 1.BPNN Flowchart

\section{Accuracy Prediction Performance}

Several methods in statistics for measuring a prediction model such as mean absolute error (MAE), Mean square error (MSE), Root mean squared error (RMSE), and mean absolute percentage error (MAPE). Measurement of prediction method aims to get the best value between the original value and the predicted value [1], [15], [16]. In this study, the MSE method was chosen to measure the accuracy of inflation rates prediction. The MSE equation uses in (2).

$$
M S E=\frac{1}{M} \sum_{t=1}^{M}\left(x_{t}-\hat{x}_{t}\right)^{2}
$$

Where, $x_{t}$ is data observation score; $x_{t}-\widehat{x}_{t}$ prediction result score; $M$ is score from time series. 


\section{Inflation Rate of Samarinda} 2012-2017

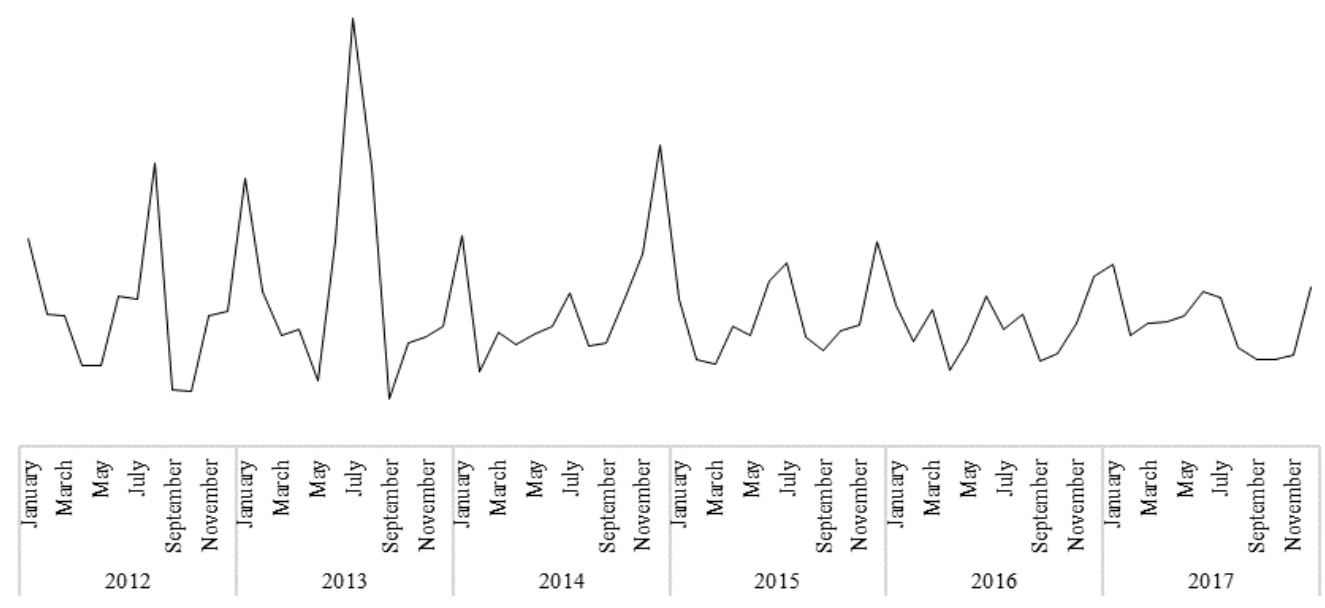

Fig. 2. Graph of Samarinda Inflation Rates (2012-2017)

\section{Results and Discussion}

This section explains the results of testing the BPNN method, which was tested on the inflation rate data in Samarinda, East Kalimantan. Based on the training rules in JST, the inflation rate data of 72 samples is divided into two parts; training data for 60 data samples (2012-2016) and test data for 12 data samples (2017). Meanwhile, the number of inputs used was five neurons $\mathrm{P}=[\mathrm{p}(\mathrm{t}-5), \mathrm{p}(\mathrm{t}-4)$, $\mathrm{p}(\mathrm{t}-3), \mathrm{p}(\mathrm{t}-2), \mathrm{p}(\mathrm{t}-1)]$, and the number output of one neuron [Output Neurons T]. On the other hand, the BPNN parameters used include the number of hidden layers, learning functions, activation functions and learning rates. The BPNN parameters can be seen in Table 2.

Table 2. Variable Test Parameter

\begin{tabular}{lc}
\hline & Parameter \\
\hline Hidden Layer & $3,4,5,6$ \\
Learning Function & trainlm, traingd, traingdx \\
Activation Function & logsig, tansig, purelin \\
Learning Rate & $0.1,0.2,0.3,0.4$ \\
\hline
\end{tabular}

In this experiment, the BPNN architecture with determined parameters was used to get the best estimate. Meanwhile, the determined architecture consists of four, they are: 5-3-3-1; 5-4-4-1; 5-5-51; and 5-6-6-1. All architectures were experimented by 12 times each. Thus, the total number of experiments was 48 times. Furthermore, the accuracy levels for all architectures were tested by using MSE. In this experiment, BPNN with a 5-5-5-1 architectural model, parameters: trainlm activation function and learning rate of 0.1 had produced MSE value of 0.00000424 . The predicted result of inflation rate in Samarinda in 2018 can be seen in Table 3 and Figure 3.

Table 3. The predicted result of inflation rate in Samarinda in 2018

\begin{tabular}{lcc}
\hline \multicolumn{1}{c}{ Month } & Normalization & Real \\
\hline January & 0.31044 & 0.58476 \\
February & 0.20529 & -0.04220 \\
March & 0.18243 & -0.17850 \\
April & 0.18243 & -0.17850 \\
May & 0.19051 & -0.13040 \\
June & 0.33221 & 0.71456 \\
July & 0.30791 & 0.56964 \\
August & 0.20327 & -0.05420 \\
September & 0.18107 & -0.18660 \\
October & 0.18107 & -0.18660 \\
November & 0.18883 & -0.14040 \\
December & 0.32961 & 0.69904 \\
\hline
\end{tabular}


Figure 3 shows that the comparison of the inflation rate patterns in previous years do not show significant differences. However, the predicted inflation rate was more stable or flat. In general, the inflation rate was relatively high at the beginning of the year, then, declined until April. Then the inflation rate climbed to the highest point in June. Then the inflation rate fell to the level of inflation in September and October, which was the lowest inflation rate and experienced an increase over the past two months.

\section{Inflation Rate Prediction in 2018}

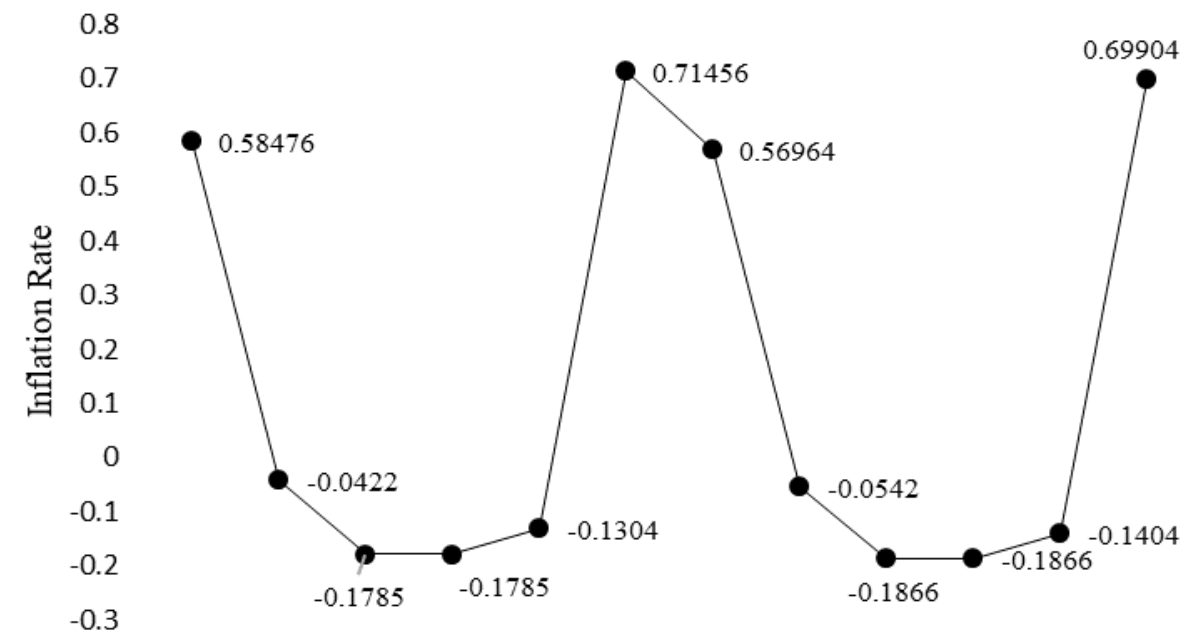

Fig. 3. Inflation rate prediction result in Samarinda (2018)

\section{Conclusion}

Analysis of the inflation rate prediction in Samarinda, East Kalimantan using the Backpropagation Neural Network (BPNN) method had been implemented. Based on the experiment results, the BPNN method with parameters such as the learning function (trainlm), activation function (logsig, tansig) and learning rate 0.1 was able to produce a fairly good level of prediction error with an MSE value of 0.00000424 . This shows that the BPNN method can be an alternative method of predicting the inflation rate in Samarinda, East Kalimantan. The implementation of a combination of other artificial intelligence methods will be the further research.

\section{References}

[1] E. U. A. Gaffar, I. Gani, Haviluddin, A. F. O. Gaffar, and R. Alfred, "A Heuristic Network for Predicting the Percentage of Gross Domestic Product Distribution," in Proceeding - 2018 International Symposium on Advanced Intelligent Informatics: Revolutionize Intelligent Informatics Spectrum for Humanity, SAIN 2018, 2019.

[2] N. R. Sari, W. F. Mahmudy, and A. P. Wibawa, "Backpropagation on neural network method for inflation rate forecasting in Indonesia," Int. J. Adv. Soft Comput. its Appl., 2016.

[3] S. Gupta and S. Kashyap, "Forecasting inflation in G-7 countries: An application of artificial neural network," Foresight, 2015.

[4] S. Mullainathan and J. Spiess, "Machine Learning: An Applied Econometric Approach," J. Econ. Perspect., vol. 31, no. 2, pp. 87-106, 2017.

[5] R. Dutu, "Why has economic growth slowed down in Indonesia? An investigation into the Indonesian business cycle using an estimated DSGE model," J. Asian Econ., 2016.

[6] N. Semuel, Hatane; Stephanie, "Analysis of the Effect of Inflation, Interest Rates, and Exchange Rates on Gross Domestic Product ( GDP) in Indonesia," Proc. Int. Conf. Glob. Business, Econ. Financ. Soc. Sci., 2015.

[7] M. J. B. Hall, D. Muljawan, Suprayogi, and L. Moorena, "Using the artificial neural network to assess bank credit risk: A case study of Indonesia,” Appl. Financ. Econ., 2009.

[8] A. Prastyo, D. Junaedi, and M. D. Sulistiyo, "Stock Price Forecasting Using Artificial Neural Network," Fifth Int. Conf. Inf. Commun. Technol., 2017. 
[9] R. Dharwal and L. Kaur, "Applications of Artificial Neural Networks : A Review," Indian J. Sci. Technol, vol. 9 No. 47, pp. 1-8, 2016.

[10] M. Lehtokangas, "Modelling with constructive backpropagation,” Neural Networks, 1999.

[11] R. Rojas and R. Rojas, “The Backpropagation Algorithm,” in Neural Networks, 2011.

[12] A. Graves, "Supervised Sequence Labelling with Recurrent Neural Networks," Stud. Comput. Intell., 2012.

[13] M. T. Hagan and M. B. Menhaj, "Training Feedforward Networks With The Marquardt Algorithm," IEEE Trans. Neural Networks, vol. 5, no. 6, pp. 989 - 993, 1994.

[14] B. M. Wilamowski and H. Yu, "Neural network learning without backpropagation," IEEE Trans. Neural Networks, 2010.

[15] Haviluddin, R. Alfred, J. H. Obit, M. H. A. Hijazi, and A. A. A. Ibrahim, “A performance comparison of statistical and machine learning techniques in learning time series data," Adv. Sci. Lett., 2015.

[16] A. Susanti, Suhartono, H. J. Setyadi, M. Taruk, Haviluddin, and P. P. Widagdo, "Forecasting Inflow and Outflow of Money Currency in East Java Using a Hybrid Exponential Smoothing and Calendar Variation Model," J. Phys. Conf. Ser., vol. 979, p. 012096, Mar. 2018. 